\title{
PRESIDENT DIRECTOR TENURE AND EARNINGS MANAGEMENT
}

\begin{abstract}
CEO tenure related of earnings management. This study also examine whether the earnings management are differencebetween early CEO tenure and final CEO tenure. The population this study is publicly traded company listed on the Indonesia Stock Exchange (IDX) in 2010-2013, best on the purposive sampling method, the total sample is 212 companies. This study use two models to examine earnings management by Jones Modified model and Roychowdury model, namely discretionary accrual model and abnormal discretionary expenses. The method of analysis in this study is paired samples $t$ Test. The result of this study shows paired samples $t$ Test indicate that earnings management issignificantly different between in the early years and final years of CEO tenure.
\end{abstract}

Keywords: Earnigs management, CEO tenure

\section{PENDAHULUAN}

Kehadiran tim manajemen yang kokoh selalu menjadi alasan penting untuk memenangkan persaingan didunia bisnis yang sulit diprediksi perubahannya (Lindrianasari dan Hartono, 2011). Pernyataan ini dapat bermakna bahwa para Chief Executif Officer (CEO) atau di Indonesia disebut sebagai direktur merupakan ujung tombak tim yang berupaya untuk meningkatkan kinerja perusahaan yang dimandatkan kepada dirinya. Direktur utama sebagai pimpinanan manajerial memiliki peran penting dalam menentukan pertumbuhan suatu entitas. Peran ini tercermin dari pendelegasian wewenang pemilik perusahaan yang diamanatkan pada dirinya ( Ross, 1973 dalam Erawan dan Ulupui, 2013).

Direktur utama memiliki tanggung jawab utama pada laporan keuangan perusahaan. Perusahaan dikatakan memiliki kinerja baik apabila menghasilkan laba yang besar dan harga saham yang tinggi (Adiasih dan Kusuma, 2011). Dalam masa jabatan direktur utama parastakeholders mengharapkan kinerja perusahaan semakin meningkat dari tahun ke tahun, hal semacam inilah yang mendorong direktur utama untuk menyajikan laporan keuangan perusahaan sebaik mungkin. Scott (2000) menyatakan pada umumnya kompensasi manajemen diberikan berdasarkan dua pengukuran kinerja manajemen yakni laba perusahaan dan harga saham.Berdasarkan kedua pengukuran ini maka era ini terjadi keprihatinan hubungan antara kompensasi Chief Executif Officer (CEO) dan manajemen laba.

Manajemen laba (Earnings Management) merupakan salah satu topik provokatif diantara beberapa topik penelitian akuntansi, hal ini mendorong dilakukannya penelitian mengenai laba perusahaan. Topik manajemen laba merupakan topik yang secara explisit melibatkan potensi kesalahan, kerugian, dan konflik (Lo, 2008). Perspektif informasi pada manajemen laba mengasumsikan bahwa informasi privat yang dimiliki oleh manajer dapat digunakan untuk memilih elemen-elemen tertentu dari peraturan pelaporan keuangan, agar manajer dapat memenuhi kesepakatan kontrak dengan para stakeholders, sebagai contoh kesepakatan mengenai kompensasi (Schipper,1989 dalam Adiasih dan Kusuma, 2011).

Pernyataan Schipper (1989) dalam Adiasih dan kusuma (2011) menyatakan bahwa manajemen laba

Korespondensi dengan penulis:

Hetty Muniroh

STIE YPPI Rembang 
terjadi ketika manajemen menggunakan keputusan tertentu dalam pelaporan keuangan serta penyusunan transaksi-transaksi yang mengubah laporan keuangan. Keputusan tertentu tersebut bertujuan untuk memberikan informasi yang salah kepada parastakeholders tentang kondisi keuangan perusahaan, serta untuk mempengaruhi penghasilan kontraktual dengan mengendalikan angka-angka akuntansi yang dilaporkan.

Holmstrom (1982) berpendapat bahwa kekhawatiran karir CEO (Chief Executif Officer) atas penilaian masyarakat terhadap kinerjanya, mendorong CEO (Chief Executif Officer) bekerja lebih keras pada awalawal tahun jabatannya dimana keinginan untuk memberikan hasil maksimal tersebut mengerucut pada pelaporan earnings overstatement. Manajemen laba dapat meningkatkan kepercayaan pemegang saham terhadap manajer. Manajemen laba berhubungan erat dengan tingkat perolehan laba atau prestasi usaha suatu organisasi, hal ini karena tingkat keuntungan atau laba dikaitkan dengan prestasi manajemen dan juga besar kecilnya bonus yang akan diterima oleh manajer. Penelitan yang dilakukan oleh Ali dan Zhang (2015) menemukan bahwa praktek earnings overstatement yang dilakukan oleh CEO, 25\% lebih besar pada awal tahun jabatannya dibandingkan dengan akhir jabatannya. Manipulasi earnings overstatement ini cenderung pada pengeluaran biaya-biaya abnormal seperti biaya R\&D(Research \& Development), biaya penjualan, biaya administrasi dan umum, serta biaya depresiasi.

Penelitian ini bertujuan untuk menguji secara empiris apakah terdapat perbedaan tingkat manajemen laba yang dilakukan direktur utama diawal jabatan dan diakhir masa jabatannya. Secara spesifik penelitian ini memberikan bukti indikasi manajemen laba pada tahun tahun awal jabatan direktur utama di Indonesia.

\section{KAJIAN PUSTAKA}

\section{Teori Agensi (Agency Theory)}

Faktor Pemicu utama dalam pergantian direktur utama adalah tidak tercapai tujuan bersama antara manajer dengan pemilik perusahaan. Karena sudah dibuktikan di banyak penelitian, bahwa semakin jauh perbedaan pencapaian kinerja perusahaan dengan harapan stakeholders dan semakin memiliki perbedaan antara kompensasi yang diperoleh manajer dengan harapan kompensasi para stakeholders, maka akan terjadi pergantian direktur utama (Wandeca, 2013).

Konsep teori agensi merupakan hubungan atau kontrak antara principal dan agent. Pada perusahaan modalnya terdiri atas saham,pemegang saham bertindak sebagai principal dan direktur sebagai agent. Agent bekerja untuk principal guna melakukan tugas tugas untuk kepentingan principal.Termasuk didalamnya yaitu pendelegasian otorisasi pengambilan keputusan dari principal ke agent (Anthony dan Govindarajan, 2005 dalam Wandeca, 2013).

Teori keagenan dapat menjelaskan hubungan antara principal dan agent.Agent berkewajiban untuk melakukan tugas bagi kepentingan principal. Namun, pada kenyataannya dalam hubungan keagenan, masingmasing pihak terdorong oleh motivasi yang berbeda sesuai dengan kepentingannya, dan apabila setiap pihak berusaha untuk mencapai atau mempertahankan tingkat kemakmuran yang dikehendaki, maka dalam hubungan ini dapat saja terjadi konflik kepentingan antara manajemen selaku agent dan pemilik perusahaan selaku principal. Sebagai manusia yang rasional, agent mengutamakan kepentingannya diatas kepentingan

Jurnal Akuntansi Indonesia 
principal, sebagai contoh dengan melakukan manipulasi atas laporan laba rugi perusahaan (Hidayah, 2009).

\section{Manajemen Laba ( Earnings Manajemen)}

Laporan keuangan disusun dengan tujuan sebagai penyedia informasi mengenai posisi keuangan perusahaan, kinerja serta perubahan posisi keuangan perusahaan yang berguna untuk para pemakai laporan keuangan dalam pengambilan keputusan ekonomi (PSAK, 2009).Berdasarkan pernyataan ini dapat dijabarkan bahwa laporan keuangan merupakan alat komunikasi yang digunakan sebagai penghubung antara pihakpihak yang memiliki kepentingan terhadap perusahaan.

Laporan keuangan juga sebagai alat bagi manajer untuk mempertanggung jawabkan pengelolaan sumber daya yang dipercayakan padanya (Adiasih dan Kusuma, 2011).Untuk mencapai tujuannya, laporan keuangan disusun dengan dasar akrual.Dasar akrual dapat jadi celah bagi manajemen untuk melakukan manajemen laba (Roychowdhury, 2006).Akses yang dimiliki manajementerhadap informasi dalam laporan keuangan, dapat dijadikan manajemen untuk menentukan bentuk dan isi informasi tambahan guna memenuhi kebutuhannya sendiri.

Manajemen laba terdiri dari berbagai macam bentuk seperti yang dijelaskan Scott (2000) sebagai berikut:

1. Taking a bath, yaitu melaporkan rugi yang besar sekaligus jika perusahaan mengalami kerugian sehingga dapat menciptakan peluang laba yang besar di masa yang akan datang. Pola ini dapat dijelaskan dalam penelitian mengenai bonus plan hypothesis, dimana manajemen akan meminimalkan laba karena kondisi perusahaan saat ini rugi.

2. Income maximization, yaitu pola manajemen laba yang dilakukan dengan cara menjadikan laba pada laporan keuangan periode berjalan lebih tinggi daripada laba sesungguhnya. Income maximization dilakukan dengan tujuan untuk memperoleh bonus yang lebih besar, meningkatkan keuntungan, serta untuk menghindari dari pelanggaran atas kontrak hutang jangka panjang. Income maximization dilakukan dengan cara mempercepat pencatatan pendapatan, menunda biaya dan memindahkan biaya untuk periode lain.

3. Income minimization, yaitu pola manajemen laba yang dilakukan dengan cara menjadikan laba pada laporan keuangan periode berjalan lebih rendah daripada laba sesungguhnya. Pola ini serupa dengan taking a bath. Income minimization dilakukan pada saat tingkat profitabilitas perusahaan cukup tinggi. Contoh penerapan pola ini adalah pada saat perusahaan melakukan manajemen laba untuk menghindari political cost.

4. Income smoothing, pola ini dilakukan untuk mendapatkan tingkat laba yang stabil dan mengurangi fluktuasi naik turunnya laba sehingga perusahaan terlihat setabil. Dalam hal ini laba akan diturunkan jika terjadi peningkatan yang tajam dan menaikkan laba jika tingkat laba yang ada berada dibawah tingkat laba ada berada dibawah tingkat laba yang ditentukan. Tingkat laba yang stabil membuat pemilik dan kreditor lebih memiliki kepercayaan terhadap manajer.

Gumanti (2000) menjelaskan bahwa manajemen laba diduga muncul atau dilakukan oleh manajer 
atau para pembuat laporan keuangan dalam proses pelaporan keuangan suatu organisasi karena mereka mengharapkan suatu manfaat dari tindakan yang dilakukan. Penjelasan Gumanti (2000) menekankan manajemen laba tidak harus dikaitkan dengan upaya untuk memanipulasi data atau informasi akuntansi namun berkaitan dengan pemilihan metode akuntansi untuk mengatur keuntungan yang dapat dilakukan karena memang diperkenankan menurut standar akuntansi (accounting regulations).

Healy dan Wahlen (1999) mendefinisikan manajemen laba sebagai berikut: "Manajemen laba terjadi ketika manajemen menggunakan pertimbangan (judgment) dalam pelaporan keuangan dan dalam penyusunan transaksi untuk mengubah laporan keuangan baik dengan tujuan untuk menyesatkan beberapa pemangku kepentingan tentang kinerja ekonomi perusahaan atau untuk mempengaruhi hasil kontrak (contractual outcomes) yang bergantung pada angka akuntansi yang dilaporkan."

\section{Masa Kerja (Tenure) Direktur Utama}

Tenure direktur utama yang dimaksudkan dalam penelitian ini adalah masa kerja direktur utama. Di Indonesia masa kerja direktur utama itu sendiri berdasarkan kebijakan perusahaan masing-masing. Jabatan direktur utama atau presiden direktur diperusahaan rata-rata 3-5 tahun, apabila tidak ada suatu hal yang menyebabkan direktur utama diberhentikan dini seperti contoh: kinerja direktur utama yang buruk menyebabkan direktur utama diberhentikan dini oleh perusahaan terkait. Penelitian ini mencoba menganalisis ada atau tidaknya manajemen laba diawal masa jabatan direktur utama atau diakhir masa jabatan direktur utama.

\section{Teori Reputasi}

Reputasi adalah suatu nilai yang diberikan kepada individu, institusi atau negara. Reputasi tidak bisa diperoleh dalam waktu singkat karena harus dibangun bertahun-tahun untuk menghasilkan sesuatu yang bisa dinilai publik.Reputasi juga baru bertahan dan sustainable apabila konsistennya perkataan dan perbuatan (Basya, 2006). Reputasi mencerminkan persepsi publik terhadap individu atau organisasi terkait dengan tindakan-tindakan yang dilakukan dimasa yang akan datang.

Para teoritisi bisnis yang menaruh perhatian pada sumber daya internal organisasi (resource based view) mengemukakan "teori reputasi" sebagai anti tesis terhadap fenomena perilaku oportunistik (Barney, 1986). Reputasi adalah komitmen psikologis dari para pelaku bisnis yang dibakukan menjadi sebuah keyakinan bersama yang akan menggerakkan aksi para individu (Levinthal, 1991) Http//Teori Reputasi//html.com diakses 17 Mei 2015.

\section{KERANGKA PEMIKIRAN TEORITIS DAN PENGEMBANGAN HIPOTESIS}

\section{Praktik Manajemen Laba Diawal Jabatan Direktur Utama dan Akhir Jabatan Direktur Utama}

Pendapat yang dikemukakan oleh Adiasih dan Kusuma (2011) menyatakan bahwa direktur utama memiliki peranan penting dalam penyusunan laporan keuangan yang kinerjanya harus dipertanggung jawabkan kepada para pemegang saham melalui rapat umum pemegang saham (RUPS). Oleh karena itu direktur utama 
berusaha semaksimal mungkin dalam mengelola laba perusahaan agar laporan keuangan terlihat bagus.

Direktur utama yang baru menjabat cenderung dinilai oleh masyarakat kurang memiliki kemampuan yang kompeten dalam memimpin perusahaan dikutip dari penyataan Holmstrom (1999) yang dikutip dari Ali dan Zhang (2015).Maka dari itu untuk mendapatkan citra baik dari masyarakat, direktur utama cenderung melakukan manajemen laba dengan pola income increasing diawal masa jabatannya dibandingkan dengan diakhir masa jabatannya.

Penelitian yang dilakukan oleh Ali dan Zhang (2015) menemukan bahwa praktik manajemen laba dengan pola earnings overstatement terjadi pada saat tahun-tahun pertama masa jabatan CEO dengan tujuan agar mendapatkan reputasi baik dari para investor atas kinerjanya.

Maka dari pernyataan diatas dapat dirumuskan hipotesis sebagai berikut :

$\mathrm{H}_{0}$ : Terdapat perbedaan tingkat praktik manajemen laba dengan proksi discretionary accrual diawal jabatan direktur utama dan diakhir jabatannya.

$\mathrm{H}_{\mathrm{a}}$ : Terdapat perbedaan tingkat praktik manajemen laba dengan proksi abnormal discretionary expenses diawal jabatan direktur utama dan diakhir jabatannya.

\section{METODE PENELITIAN}

\section{Data dan Pemilihan Sampel}

Penelitian ini menggunakan data sekunder. Data sekunder umumnya berupa catatan, bukti, laporan historis yang diarsipkan atau didokumenkan baik yang dipublikasi maupun tidak dipublikasikan. Data yang diperlukan dalam penelitian ini diperoleh dari laporan keuangan tahunan perusahaan yang didapat dari berbagai macam sumber yaitu Indonesian Capital Market Directory (ICMD), idx statistic dan Bursa Efek Indonesia (BEI). Data yang digunakan tersebut merupakan data tahunan perusahaan mulai dari 2010-2013. Kurun waktu tersebut dipilih karena keterbatasan data yang dimiliki dan keterbatasan waktu yang tersedia.

Sampel dalam penelitian ini adalah perusahaan manufaktur yang terdaftar di Bursa Efek Indonesia (BEI). Pemilihan perusahaan manufaktur sebagai sampel berdasarkan beberapa pertimbangan seperti: mayoritas perusahaan yang terdaftar di BEI adalah perusahaan manufaktur, serta mengurangi bias karena perbedaan karakteristik atau jenis perusahaan.

Metode pengambilan sampel dalam penelitian ini menggunakan purposive sampling. Sampel dipilih dengan kriteria tertentu untuk mendapatkan sampel representative. Kriteria pengambian sampel adalah sebagai berikut:

1. Penerbitan laporan keuangan secara berturut-turut dari tahun 2010-2013.

2. Data pergantian direktur utama dicantumkan dalam laporan RUPS.

3. Laporan keuangan diterbitkan dalam mata uang rupiah.

\section{DEFINISI OPERASIONAL VARIABEL DAN PENGUKURAN VARIABEL}

\section{Manajemen Laba}

Variabel dependen dalam penelitian ini adalah manajemen laba. Manajemen laba dalam penelitian ini 
menggunakan dua model pengukuran yang berbeda yaitu dengan model discretionary accrual dan abnormal discretionary expenses. Roychowdhury (2006), Cohen et al (2008) berpendapat bahwa direktur utama dapat melakukan manajemen laba dengan dua cara yaitu manipulasi akrual dan manipulasi faktor riil. Manipulasi akrual yang diproksikan dengan discretionary accrual dapat didefinisikan secara sederhana sebagai judgment direktur utama yang digunakan secara sengaja untuk manipulasi catatan akuntansi dengan tujuan untuk menampilkan kondisi keuangan tertentu kepada para stakeholders (Healy dan Wahlen, 2009 dalam Adisih dan Kusuma, 2011). Sedangkan manipulasi faktor riil diproksikan dengan abnormal discretionary expenses. Data mengenai penghitungan aktivitas riil yang diukur dengan abnormal discretionary expensesadalah total aktiva, aktiva tetap, piutang, pendapatan, laba bersih, pengeluaran diskresioner, dan arus kas dari operasi.

Berikut adalah rumus untuk menghitung discretionary accrual:

\section{Discretionary Accrual}

Penelitian ini menggunakan cross-sectional model of accruals yang diusulkan oleh McNichols (2002) untuk mengestimasi diskreioner akrual. Model ini mengkombinasi dari model Jones (1991) dan Dechow dan Dichev (2002). Kombinasi model ini yaitu discretionary accrual dan abnormal discretionary expenses.

Langkah-langkah dalam menghitung akrual diskresioner dengan Modified Jones adalah sebagai berikut:

$T A C=N_{i t}-C F O_{i t}$

Nilai total accrual (TA) yang diestimasi dengan persamaan regresi OLS sebagai berikut :

$\frac{T A_{i t}}{A_{i t-1}}=\beta_{1}\left(\frac{1}{A_{i t-1}}\right)+\beta_{2}\left(\frac{\triangle R E V_{i t}}{A_{i t-1}}\right)+\beta_{3}\left(\frac{P P E_{i t}}{A_{i t-1}}\right)+\varepsilon_{i t}$

Dengan menggunakan koefisien regresi diatas nilai non discretionary accrual (NDA) dapat dihitung dengan rumus :

$\frac{T A_{i t}}{A_{i t-1}}=\beta_{1}\left(\frac{1}{A_{i t-1}}\right)+\beta_{2}\left(\frac{\Delta R E V_{i t}-\Delta R E C_{i t}}{A_{i t-1}}\right)+\beta_{3}\left(\frac{P P E_{i t}}{A_{i t-1}}\right)+\varepsilon_{i t}$

Selanjutnya discretionary accrual (DA) dapat dihitung sebagai berikut:

$D A_{i t}=T A-N D A_{i t}$

Dimana:

DAit = Discretionary Accruals perusahaan $i$ pada periode ke $t$

NDAit $=$ Non Discretionary Accruals perusahaan $i$ pada periode ke $t$

TAit $\quad=$ Total akrual perusahaan $i$ pada periode ke $t$

Nit $=$ Laba bersih perusahaan $i$ pada periode ke- $t$

CFOit = Aliran kas dari aktivitas operasi perusahaan $i$ pada periode ke $t$

Ait-1 = Total aktiva perusahaan $i$ pada periode ke $t-1$

$\Delta$ Revit $=$ Perubahan pendapatan perusahaan $i$ pada periode ke $t$ 


$$
\begin{array}{ll}
\text { PPEt } & =\text { Aktiva tetap perusahaan pada periode ke } t \\
\Delta \text { Rect } & =\text { Perubahan piutang perusahaan } i \text { pada periode ke } t \\
e & =\text { error } \\
\beta 1, \beta 2, \beta 3 & =\text { koefisien regresi }
\end{array}
$$

Pengukuran lain manajemen laba dalam penelitian ini manipulasi aktivitas riil yaitu dengan menggunakan abnormal discretionary expenses model Roychowdury (2006), untuk memudahkan komparasi atau perbandingan manajemen laba yang dilakukan direktur utama pada tahun pertama dan tahun berikutnya (Dechow dan Sloan,1991; Murphy and Zimmerman,1993 dalam Ali dan Zhang, 2015).

Berikut adalah rumus yang digunakan untuk menghitung abnormal discretionary expenses:

\section{Abnormal Discretionary Expenses}

Persamaan untuk menghitung arus kas operasional normal

$$
\frac{C F O_{i t}}{\text { Ait }-1}=\alpha_{1} \frac{1}{\text { Ait }-1}+\alpha_{2} \frac{S_{i t}}{\text { Ait }-1}+\frac{\Delta S_{i t}}{\text { Ait }-1}+\varepsilon_{i t}
$$

Persamaan untuk menghitung biaya produksi normal

$$
\frac{\operatorname{prod}_{i t}}{\text { Ait }-1}=\alpha_{1} \frac{1}{\text { Ait }-1}+\alpha_{2} \frac{S_{i t}}{\text { Ait }-1}+\alpha_{3} \frac{\Delta S_{i t}}{\text { Ait }-1}+\frac{\Delta S_{i t-1}}{\text { Ait }-1} \varepsilon_{i t}
$$

Persamaan untuk menghitung pengeluaran biaya diskresioner tidak normal

$$
\frac{\operatorname{DISEXP}_{i t}}{\text { Ait }-1}=\alpha_{1}+\alpha_{2} \frac{1}{\text { Ait }-1}+\frac{S_{i t}}{\text { Ait }-1}+\alpha_{3} \frac{\Delta S_{i t-1}}{\text { Ait }-1} \varepsilon_{i t}
$$

Persamaan untuk menghitung manajemen laba riil

AREALit $=$ APRODit - DISEXPit - ACFOit

Dimana:

DISEXPit = pengeluaran diskresioner (jumlah biaya R\&D, biaya iklan, administrasi dan umum perusahaan $i$ pada tahun $t$ )

Ait $\quad=$ total asset perusahaanipada tahun $t$

Sit $\quad=$ pendapatan (penjualan) perusahaan $i$ pada tahun $t$

$\Delta S_{i t} \quad=$ Total penjualan perusahaan $i$

Prod $=$ biaya produksi pada perusahaan $i$ tahun ke $t$

ACFOit = Arus kas opersional abnormal

APRODit = Biaya produksi abnormal

ADEXPit = Abnormal discretionary expenses

AREALit = Manajemen laba riil 


\section{Tenur Direktur Utama}

Variabel independen dalam penelitian ini adalah tenure direktur utama. Tenure (masa kerja) direktur utama merupakan periode waktu jabatan direktur utama (president director) perusahaan. Tenure merupakan jangka waktu seorang direktur utama menjabat, direktur utama dibedakan menjadi dua yaitu direktur utama baru dan direktur utama lama.Direktur utama baru ataupun direktur utama lama pada umumnya melakukan manajemen laba dengan tujuan dan alasan tertentu.

Tenure direktur utama digambarkan dengan timeline untuk mendefinisikan terkait dengan tahun jabatan CEO.Variabel tenur direktur utama diukur dengan dummy dimana nilai 1 diberikan untuk periode jabatan 1 tahun pertama dan nilai 0 untuk tahun yang lain.

\section{Pengujian Hipotesis Uji Beda T Test (Related Samples)}

Uji hipotesis yang digunakan untuk menguji hipotesis komparatif antara variabel dependen yaitu manajemen laba dan dua variabel independen yaitu awal tahun dan akhir tahun. Pengujian ini digunakan untuk mengetahui apakah ada perbedaan antara manajemen laba yang terjadi diawal dan diakhir tahun masa jabatan direktur utama.

Hasil pengujian uji beda paired samples untuk manajemen laba dengan proksi abnormal discretionary expenses disajikan pada tabel 1, terlampir.

Tabel 1 menunjukkan nilai mean antara manajemen laba dengan prosi abnormal discretionary expenses diawal jabatan direktur utama dan akhir jabatan direktur utama memiliki perbedaan yaitu 8563 dan 9495 . Hal ini menunjukkan bahwa praktik manajemen laba lebih besar terjadi diakhir tahun jabatan direktur utama. Sedangkan nilai t hitung $-0,566$ dengan tingkat signifikasi 0,572. Dari hasil data statistik tersebut bahwa adanya perbedaan nilai rata-rata manajemen laba yang terjadi diawal tahun jabatan direktur utama dengan akhir jabatan direktur utama namun perbedaannya tidak signifikan menurut statistik.Pernyataan hipotesis Ho yang menyatakan tidak terdapat perbedaan tingkat praktik manajemen laba diawal jabatan direktur utama dan diakhir jabataanya diterima.

Tabel 2 menunjukan hasil dari pegujian bedapaired samples t test untuk manajemen laba awal tahun dan akhir tahun dengan proksi discretionary accrual. Terlampir.

Teori reputasi menyatakan bahwa reputasi seseorang atau organisasi akan melekat pada dirinya apabila seseorang berhasil memberikan citra baik pada orang lain. Reputasi tidak serta merta didapatkan dalam waktu singkat, butuh proses untuk mendapatkannya. Reputasi mencerminkan persepsi publik terhadap individu atau organisasi terkait dengan tindakan-tindakan yang dilakukan dimasa yang akan datang. Seperti halnya Direktur utama yang baru menjabat agar bisa memberi kesan dan bereputasi baik dimata para pemegang saham, perlu melakukan suatu tindakan yang menjadikan persepsi terhadap dirinya menjadi lebih baik.

Hasil penelitian menunjukkan hasil bahwa praktik manajemen laba dengan proksi discretionary accrual dipengaruhi oleh masa jabatan awal (early years) direktur utama.Perbandingan signifikasi hasil antara masa jabatan awal dan masa jabatan akhir menunjukkan besarnya tingkat manipulasi manajemen laba. Reputasi serta citra baik yang didapatkan oleh direktur utama diawal masa jabatannya dirasa penting untuk

Jurnal Akuntansi Indonesia 
keberlangsungan karir direktur dimasa yang akan dating, maka agar mendapatkan citra baik tersebut direktur utama melakukan praktik manajemen laba guna memperbaiki nilai laba yang dilaporkan.

Hasil penelitian ini sejalan dengan penelitian yang dilakukan oleh Ali dan Zang (2015) yang menyatakan manajemen laba cenderung terjadi diawal jabatan CEO dibandingkan diakhir masa jabatannya.

\section{SIMPULAN}

Hasil uji beda menunjukkan bahwa terdapat perbedaan praktik manajemen laba pada proksi discretionary accrual diawal jabatan direktur utama dengan akhir masa jabatannya. Sedangkan untuk proksi abnormal discretionary expenses menunjukan adanya perbedaan manajemen laba diawal jabatan dan diakhir jabatan, namun perbedaannya tidak signifikan menurut statistic.

\section{DAFTAR PUSTAKA}

Adiasih, priskila dan Indra Wijaya Kusuma.2011.Manajemen Laba Pada Saat Pergantian Direktur Utama(Dirut) Di Indonesia. Jurnal Akuntansi dan Keuangan, Vol 13, no 2, November 2011: 67-79.

Ali, Ashiq and Weining Zhang.2015.CEO Tenure and Earnings Management. Journal Of Financial and Economic. 59, 60-79.

Amalia, Waode intan. 2015. Analisis Implementasi Coorporate Governance terhadap capital structure Pada Perbankan Syariah Di Indonesia. Skripsi Universitas Islam Sultan Agung. Semarang.

Anisa, Elfira. Pengaruh Kompensasi Bonus dan Leverage Terhadap Manajamen Laba Studi Empiris pada Perusahaan Manufaktur yang Terdaftar di Bursa Efek Indonesia .Skripsi yang dipulikasi Universitas Negeri Padang.

Ardhiansyah, Danis. 2014. Pengaruh size, Leverage, profitability, capital intensity ratio, dan Komisaris Independen terhadap Effective Tax Rate studi empiris terhadap perusahaan manufaktur yang terdaftar di Bursa Efek Indonesia periode 2010-2012 Skripsi Dipublikasikan.Universitas Diponegoro.

Astuti,Yuni. 2008. Statistik II. Jakarta: Salemba Empat.

Barney, J.B. 1986. Strategic Factor Markets: Expectation, Luck, and the Theory of Business Strategy. Management Science.Issue 32.p.1512-1514

Canad Inc.Wandeca, Jeni Sevi.2013. Analisis Pengaruh Pergantian Chief Executive Officer (CEO) Terhadap Praktek Manajemen Laba (Studi Pada Perusahaan BUMN dan Non BUMN di Bursa Efek Indonesia). Skripsi

Cheng, S., 2004.R\&D expenditure and CEO compensation.Accounting Review 79,305-328.

Desi Anistya Winta, dkk. 2014. Keterkaitan Antar Komite Audit, Kompensasi CEO, dan Manajemen Laba dengan Fee Audit Perusahaan studi pada perusahaan manufaktur yang terdaftar di BEl. Simposium Nasional Akuntansi XVII .Lombok Mataram .24 - 27 September 2014.

Dewi, Saptantinah. 2002. Analisis faktorfaktor yang mempengaruhi motivasi manajemen laba di seputar rightissue. Skripsi tidak dipublikasi.

Elfira, A. (2014). Pengaruh Kompensasi Bonus Dan Leverage Terhadap Manajemen Laba.Jurnal Akuntansi Vol 2 No 2. 
Elfira, Anisa. 2014. Pengaruh Kompensasi Bonus dan Leverage terhadap Manajemen Laba studi empiris terhadap perusahaan manufaktur yang terdaftar di Bursa Efek Indonesia periode 2009-2012 Skripsi Dipublikasikan. Universitas Negri Padang.

Erawan, I Gede Pandita dan I Gusti Ketut Ageng Ulupui.2013.Manajemen Laba Sebelum dan Sesudah Pergantian Chief Executif Officer (CEO). E-jurnal Akuntansi Universitas Udayana 3.1 ,55-72.

Fama, Eugene, and Michael Jensen. 1983. Separation of ownership and control. Journal of Law and Economics 26. 301-325.

Ghozali, Imam. 2013. Aplikasi Analisis Multivariate dengan Program IBM SPSS 21 Update PLS Regresi. Semarang : badan Penerbit fakultas Ekonomi Universitas Diponegoro.

Ghozali, Imam. 2016. Analisis Multivariate dengan Program SPSS.Semarang : badan Penerbit fakultas Ekonomi Universitas Diponegoro.

Gujarati . 2003. Dasar-Dasar Ekonometrika. Jakarta : Salemba Empat

Gujarati dan Porter. 2009. Dasar-Dasar Ekonometrika. Jakarta : Salemba Empat

Gumanti, T.A. 2000.Indikasi Eraning Management pada Initial Public Offering.Journal accounting. Universitas Jember.

Handayani, Rr Sri, and Agustono Dwi Rachadi. Pengaruh Ukuran Perusahaan Terhadap Manajemen Laba. Jurnal bisnis dan akuntansi 11.1 (2009): 33-56.

Healy, P. 1985. The Effect of of Bonus Schemes on Accounting Decisions.Journal ofAccounting and Economics, 7:85-107.

Herusetya, Antonius. 2010. Pengaruh Sistem Informasi Tehnologi Elektronik Atas Task Performance Auditor Kantor Akuntan Publik Big 4. Jurnal Akuntansi dan Keuangan Indonesia (JAKI), Vol 7, No 1, Juni 2010, hal 1-17 (ISSN 1829-8494). No. Akreditasi : 110/DIKTI/Kep/2009.

Hidayah, Chusnul. 2009. Pengaruh mekanisme Corporate Governance dan Karakteristik Perusahaan Terhadap Pengungkapan Sosial:Studi empiris pada Perusahaan Riil Estate dan Properti yang Terdaftar di BEl. Skripsi tidak dipublikasikan. Universitas Diponegoro.

Holmstrom, B.,1982. Moral hazard inteams.Bell Journal of Economics 13,324-340.

http//reputasi.html.com. diakses pada tanggal 17 Mei 2015. Pukul 19.00.

http://www.pengertianpakar.com/2014/12/pengertian-dan-tujuan-pengawasan.html\# diakses pada tanggal 24 februari 2015.

Ikatan Akuntan Indonesia.2009.Pernyataan Standar Akuntansi Keuangan: Kerangka Dasar Penyusunan Laporan Keuangan.Salemba Empat: Jakarta.

Indriani dan Nurkolis. 2002. Manfaat dan Fungsi KOmite Audit Dalam mewujudkan Tata Pengelolaan Perusahaan yang Baik (Good Corporate Governance): Persepsi Manajemen Perusahaan Go Public. Journal akuntansi Brawijaya, Volume 2, No 1, Maret 2002.

Khan, Md. Habib Uz-Zaman. 2010. The Effect of Coorporate Governance Elements on Corporate Social Responsibility (CSR) Reporting (Empirical Evidance from Private Commercial Banks of Bangladesh). International Journal 
of Law And Management. Vo;I. 52, No. 2.

Lee, Rice. Pengaruh Leverage, Kepemilikan Institusional, Ukuran dan Nilai Perusahaan Terhadap Tindakan Manajemen Laba.JWEM (Jurnal Wira Ekonomi Mikroskil) 3.1 (2013): 41-50.

Lindrianasari dan Jogiyanto Hartono. 2011. Kinerja Akuntansi dan Kinerja Pasar Sebagai Anteseden dan Konsekuensi atas Pergantian Chief Executif Officer (CEO) : Studi kasus dari Indonesia. http://www.stipena. ac.id/AKPM 13.Diunduh 16 Februari 2015.

Lo, Kin.2008.Earnings Mangement and Earnings Quality. Journal of Accounting and Economic 45, 350-357.

Malayu, Hasibuan. 2010. Manajemen Sumber Daya Manusia囚. Jakarta: Bumi Aksara

Maydew, Edward L.1997. Tax-Induced Earningss Management by Firms with Net Operating Losses.Journal of Accounting Research, Spring: 83-96.

Muniroh, Hetty.2013. Akuntanbilitas Keuangan dan Penerapan PSAK Syariah pada Lembaga Amil Zakat Di semarang. Skripsi Tidak Dipublikasikan.Universtas Islam Sultan Agung.

Myers, James N., Myers, Linda A., dan Omer, Thomas C. 2003. Exploring the Term of The Auditor-Client Relationship and the Quality of Earningss: A Case for Mandatory Auditor Rotation. The Accounting Review 78(3): 779799.

Pujiati, E. J., \& Arfan, M. (2013).Struktur Kepemilikan dan Kompensasi Bonus Serta Pengaruhnya Terhadap Manajemen Laba Pada Perusahaan Manufaktur Yang Terdaftar di Bursa Efek Indonesia Tahun 2006-2010. Jurnal Telaah dan Riset Akuntansi, 122-139.

Putri, Dwi N. 2013. Pengaruh Struktur Kepemilikan dan Kualitas Audit Terhadap Manajemen Laba.Skripsi yang dipublikasikan. Semarang. Universitas Diponegoro Semarang.

Rahardjo, Adisasmita, 2011. Pengelolaan Pendapatan \& Anggaran Daerah. Penerbit Graha Ilmu : Yogyakarta.

Scott William R. 2006. Financial Accounting Theory. Edisi Keempat. USA: Prentice Hall.

Scott, William R. 2000. Financial Accounting Theory, Edisi Kedua, Prentice-Hall.

Scott, William R. 2006. Financial Accounting Theory.International Edition. New Jersey: Prentice Hal.

Shochrul R, Ajija, dkk. 2011. Cara cerdas menguasai EVIEWS. Jakarta : salemba empat.

Sonali, H. J. M. Karpoff, dan R. Nahata. 2011. Internal Corporate Governance, DIREKTUR UTAMA turnover, and Earnings Management. Journal of Financial Economic 104, 44-69.

Undang- undang Republik Indonesia Nomor 40 Tahun 2007 tentang Perseroan Terbatas.

Wahyuningsih, panca.2009.Pengaruh Kepemilikan Instutisional dan Coorporate Governance Terhadap Maanajemen Laba. Jurnal Akuntansi Indonesia vol 4 ,No 2, Desember 2009: 78-93.

Wandeca, Jenny Sevi. 2013. Analisis Pengaruh Pergantian Chief Executive Officer (CEO) Terhadap Praktek Manajemen Laba Studi Pada Perusahaan BUMN dan Non BUMN di Bursa Efek Indonesia. Skripsi yang dipublikasikan Universitas Lampung.

Widarjono, Agus. 2013. Ekonometrika Pengantar dan Aplikasinya.Yogyakarta: UPP STIM YKPN. ISBN: 9789798532707

Widarjono.Agus .2007.Ekonometrika Teori dan Aplikasi untuk Ekonomi dan Bisnis.Ekonisia.Yogyakarta. 


\section{JURNAL AKUNTANSI INDONESIA}

Widyaningdyah, Agnes Utari. 2001. Analisis Faktor-faktor yang Berpengaruh Terhadap Earnings Management Pada Perusahaan Go Public Di Indonesia. Jurnal Akuntansi dan Keuangan, November, Vol 3.No 2.

Wijaya, Veronika Abdi dan Yulius, Jogi Cristiawan. 2014. Pengaruh Kompensasi Bonus Laverage Terhadap Pajak dan Earnings Management Pada Perusahaan Manufaktur yang Terdaftar diBursa Efek Indonesia. Tax and accounting review Vol 4. No 1.

www.idx.co.

Jurnal Akuntansi Indonesia 


\section{LAMPIRAN}

\section{Tabel 1}

Hasil uji beda Manajemen Laba proksi Aktivitas Rill

Paired Samples statistics

\begin{tabular}{lllll}
\hline & Mean & $\mathrm{N}$ & Std. Deviation & Std. Error Mean \\
\hline Pair $1 \quad$ Areal Awal Tahun & .8563 & 212 & 5.88664 & .40430 \\
\hline Areal Akhir Tahun & .9495 & 212 & 5.56599 & .38227 \\
\hline
\end{tabular}

Paired Samples Test

\begin{tabular}{|c|c|c|c|c|c|c|c|c|}
\hline & \multicolumn{5}{|c|}{ Paired Differences } & \multirow[b]{3}{*}{$\mathrm{T}$} & \multirow[b]{3}{*}{ df } & \multirow{3}{*}{$\begin{array}{l}\text { Sig. } \\
\text { (2-tailed) }\end{array}$} \\
\hline & \multirow[b]{2}{*}{ Mean } & \multirow{2}{*}{$\begin{array}{l}\text { Std. Devia- } \\
\text { tion }\end{array}$} & \multirow{2}{*}{$\begin{array}{l}\text { Std. Error } \\
\text { Mean }\end{array}$} & \multicolumn{2}{|c|}{$\begin{array}{l}\text { 95\% Confidence } \\
\text { Interval of the Differ- } \\
\text { ence }\end{array}$} & & & \\
\hline & & & & Lower & Upper & & & \\
\hline $\begin{array}{c}\text { Pair } 1 \text { AREALawal - AR- } \\
\text { EALakhir }\end{array}$ & -.09321 & 2.39575 & .16454 & -.41756 & .23115 & -.566 & 211 & .572 \\
\hline
\end{tabular}

Sumber : Data sekunder yang diolah 2016

Tabel 2

Hasil uji beda Manajemen Laba proksi Model Discretionary Accrual

\begin{tabular}{|c|c|c|c|c|c|}
\hline \multicolumn{6}{|c|}{ Paired Samples statistics } \\
\hline & & Mean & $\mathrm{N}$ & Std. Deviation & Std. Error Mean \\
\hline \multirow[t]{2}{*}{ Pair 1} & DAawal & .0949 & 211 & .32196 & .02216 \\
\hline & DAakhir & .0773 & 211 & .34049 & .02344 \\
\hline
\end{tabular}

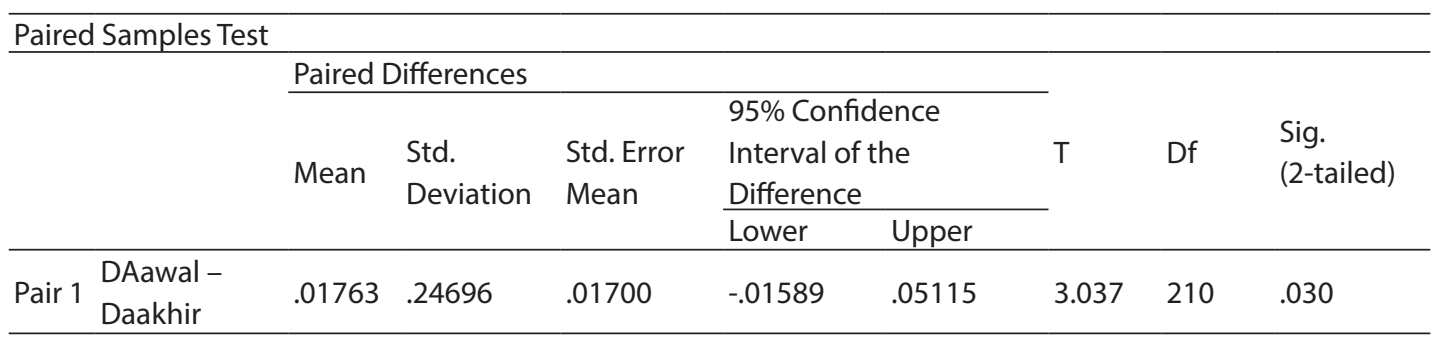

Sumber : Data sekunder yang diolah 2016 


\section{Gambar 1}

Time line Direktur

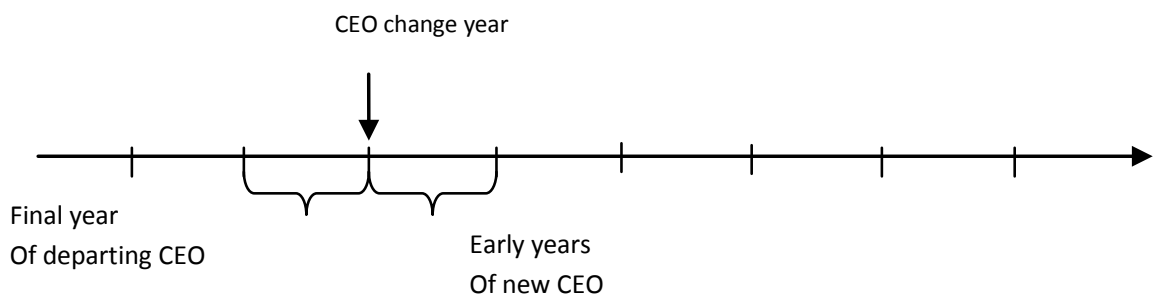

